\title{
NOVEL IDEAS ON ENGINEERING EDUCATION IN BANGLADESH
}

\author{
K. B. Kabir ${ }^{*}$, M. S. Khan ${ }^{2}$ and I. Mahmud ${ }^{1}$ \\ ${ }^{1}$ Department of Chemical Engineering, Bangladesh University of Engineering \& Technology, Dhaka-1000, Bangladesh \\ ${ }^{2}$ Australian Pulp and Paper Institute, Dept. of Chemical Engineering, Monash University, Clayton, VIC 3800, Australia
}

Received 12 May 2008; received in revised form 30 May 2008

\begin{abstract}
In recent times Bangladesh celebrated 60 years of engineering education. The engineering education in Bangladesh has gone through different changes in its life span; however, there are plenty to improve to cope with the world trend of engineering. Industrial diversification, changes is socio-economic structures, and advancements of new sciences and technologies are forcing changes in engineering curriculum to keep the content compatible. This paper discusses some of the new ideas of engineering education practiced at different parts of the world. It also offers a review of the new approaches which can be applied in Bangladesh to make the engineering students more competitive and compatible, so that they can go through a lifelong learning process and confront the changes in engineering career. The overall goal of this article is to help improving the engineering education system in Bangladesh where students can develop themselves as independent and interdependent learners.
\end{abstract}

Keywords: Integrated curriculum; Effective Teaching; Multidimensional competition; Student evaluation.

\section{INTRODUCTION}

The journey of engineering education in Bangladesh started with the establishment of Dhaka Engineering College in 1948. Dhaka Survey School, established in 1876, became Dhaka Engineering College (later renamed as Ahsanullah Engineering College) with undergraduate programs in Civil, Electrical, Mechanical and Chemical engineering. Later on, to facilitate postgraduate studies and research, Ahsanullah Engineering College was upgraded to the status of a university under the name of East Pakistan University of Engineering and Technology (EPUET) in 1962. After liberation the university found its current name: Bangladesh University of Engineering and Technology (BUET). BUET now offers programs through fifteen departments and also has several research centres and institutes. Alongside BUET, four other public engineering universities and some private universities are also offering engineering courses. Engineering education has been booming throughout all these years. Engineering discipline is highly preferred by the students with academic excellence due to high market demand, social prestige and diversity.

The industrialization in Bangladesh started mainly with agro based industries since 1950. From the seventies, the pace of industrialization increased and noticeably diversified. The vision of developing engineering education was to meet the increasing demand of engineers as the country was thriving to develop the industrial sectors and infrastructures. In this process, the engineering education system has produced a good number of well skilled engineers, who not only helped the country in the industrial development but also proved their skills at the world level.

The global scenario is changing rapidly with the changes in technology and socio-economic structures, and the responsibilities of the engineers are being affected too. Rugarcia et al. had pointed out seven features that will pose challenges to future engineers, which are as follows: expansion of information, diminishing boundaries between the disciplines, globalized economy, endangered environment, resource constraints, emerging social responsibilities and rapid changes in technology [1]. To cope with changing situation, engineers must have the ability to identify, formulate and solve new engineering problems, and must understand the impact of their solutions in a global and societal context. They must have effective communication skills to function properly in a multidisciplinary working environment and must understand their professional and ethical responsibilities. Moreover, they have to go through a lifelong learning process to manage changes around them. To equip with such skills, some changes are needed in the curriculum, teaching methods and delivery modes. This paper gives a brief discussion about the changes and new techniques in engineering education.

In engineering education system real-life-problem based learning can be an effective way as it helps students to solve open-ended engineering problems [2]. Using technology as a teaching tool saves time and laborious calculation processes and gives the students sufficient time to think creatively. "Mixing lecture" based classes with hands-on laboratories and trips to the real 
engineering sites strengthen the learning abilities of students. Interaction with industry personnel gives the students ideas about their future job prospects and responsibilities. Engineering books seldom talk about how practicing engineers operate, the problem they face and the way they solve the problems. Such industrial know-how motivates students, as they can correlate their course material with engineering profession. Moreover, multidimensional competition among the students can help them to develop different skills which will be helpful in their carrier.

The objective of this paper is to discuss the ongoing trends of engineering education both in national and global contexts. This paper proposes some new approaches, which can be applied as useful tools to make the local students more competitive and confident in their academic career as well as professional engineering. The overall goal is to develop the students as independent and interdependent learner.

\section{CURRENT TRENDS OF ENGINEERING EDUCATION: BANGLADESH PERSPECTIVE}

At the beginning, the academic programs of Ahsanullah Engineering College were based on the British undergraduate curriculum [3]. In 1953, engineering curriculum went through significant changes when a linkage program was developed with Texas Agriculture and Mechanical College (now Texas A \& M University) of USA [4]. Since then, the institution has maintained its relationship with foreign universities through different linkage programs. These programs were planned for the development of the staff, course-curricula, laboratories and library facilities [5].

To cope with the changes and advances in the technological fields, as well as, to bear out the requirements of a developing country, the engineering curricula in Bangladesh needs to go through continuous modernization. Table 1 shows the different development phases of the evolving engineering curricula. To understand what we need, first we have to find out where we are. But, no attempt has been made to determine with any precision where our engineering curricula stand today.

Changes in the teaching methodologies are less apparent. Class room lectures are still only means of imparting education. Need for updating nontechnical portion of the curriculum (humanities, management, English, verbal communication, scientific writing skill, etc.) as well as student evaluation are yet to be underscored. Evaluation of the students is based on only a few traditional examinations and often the evaluation process does not reflect the true picture. Evaluation methods are actually framed by the governing body of the institutions. However, sometimes this practice does not allow the teachers to adopt advanced evaluation methods which can be better for the students.

Industry-university relationship is at minimum level for most of the institutions. Since engineering programs were transplanted from the industrialized western world to an agricultural economy, growth of the education could not be organically linked with the industrial and technological fields of the country. Even today, interaction between the industries and engineering universities is limited mainly in the area of consultancy. Involvement of industries in research and development (R \& D) are very few.

Postgraduate programs in engineering were started in 1962 when Ahsanullah Engineering College was upgraded to a university. These programs cannot be rated as very successful. Dropout rate at this level is dreadfully high. For example, only $12.6 \%$ of the enrolled students have successfully completed their M.Sc. Engineering degree at BUET between 2000 and 2006 [7]. Figure 1 clearly shows current status of the postgraduate studies at BUET. Some major reasons of postgraduate dropout can be identified: very limited number of student scholarship, constraint of research facilities, limited number of courses, lack of varieties in courses compared to the global context, lack of recognition in job market, lack of self-motivation of a student and of academic staff, etc.

Table 9: Evolving Engineering Curricula [6]

\begin{tabular}{|c|c|c|}
\hline $\begin{array}{c}\text { Curriculum } \\
\text { Development Phases }\end{array}$ & $\begin{array}{c}\text { Major Emphasis in Existing } \\
\text { Curricula }\end{array}$ & $\begin{array}{c}\text { New and Emerging Area/Issues Being } \\
\text { Valued for Emphasis }\end{array}$ \\
\hline FIRST & $\begin{array}{c}\text { Industrial Arts and Hands-on Training } \\
\text { in Technologies }\end{array}$ & Engineering Design \\
\hline SECOND & Engineering Design & Engineering Science \\
\hline THIRD & Engineering Science & Basic Science and Mathematics \\
\hline FOURTH & Engineering and Basic Science & $\begin{array}{c}\text { Environmental Concerns, Humanities } \\
\text { and Social Science }\end{array}$ \\
\hline FIFTH & New Disciplines of Engineering & $\begin{array}{c}\text { Inter-Disciplinary Studies, Interfacing } \\
\text { of Engineering and Other Professions }\end{array}$ \\
\hline
\end{tabular}



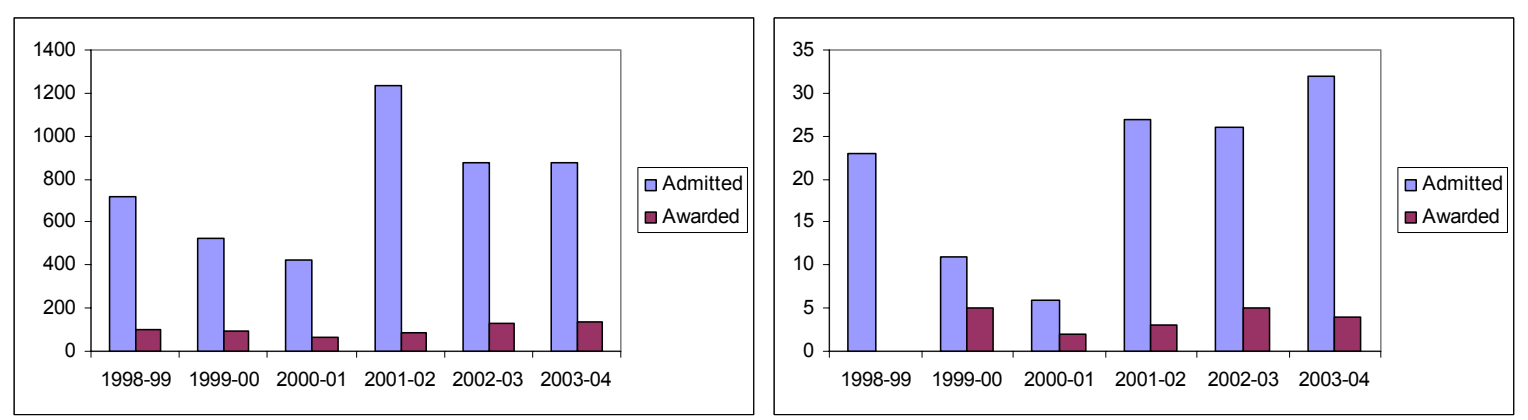

Figure 2: Performance of M.Sc. and PhD Students in BUET [8]

\section{CURRENT TRENDS OF ENGINEERING EDUCATION: GLOBAL PERSPECTIVE}

Engineering practices are changing throughout the world. Industries and emerging technologies are playing the major role of this change. Multinational companies are hiring engineers in their projects, which are globally distributed. As a result, an engineer has to be equipped to compete with the engineers who graduate from different universities of the world.

Assurance of the quality of education is an acceptable solution to support the changes in education of any discipline. An authorized panel should structure the general criteria for basic level programs to accommodate ongoing changes. Accreditation in the regional and national level is not a new concept. Different professional associations are active to control the educational quality in developed countries like USA, Canada, Australia and Germany, as example, ABET for engineering in USA, Engineers Australia and Institute of Chemical Engineers (IChemE) for Australian engineering education, etc. Even India and Pakistan also have their accreditation associations. Besides, there are collaborations among the top universities in the national and international levels, such as, Go8 in Australia, G13 in Canada, Coimbra Group in Europe and Universitas 21 as an international network of research-intensive universities.

Quality of education cannot be assured without proper faculty. Most engineering faculties do not go through a formal course in pedagogy. They get their training as researchers and after joining as faculty members they enter their classrooms without having enough idea of what to do there. Most of them follow methods their teachers followed, who also never received formal training on teaching methods. Teacher education in engineering is now being emphasised more than ever. John Stice is the first person to initiate courses for teacher education followed by Phil Wankat and Frank Oreovicz. Since 1972, John Stice has been offering a course in teaching engineering at the University of Texas at Austin [9]. Phil Wankat and Frank Oreovicz also started a similar course at Purdue University in early 1980s' [10]. In the process they wrote a whole book containing learning models, various teaching techniques, evaluation methods etc. [11].

Workshops and seminars on effective teaching and faculty development program are now regularly organized by American Society for Engineering Education (ASEE), National Effective Teaching Institute (NETI), Frontiers in Education (FIE) and others. Besides, some of the universities are also assigning an experienced faculty as teaching mentor for a new faculty member $[9,12]$.

Effective teaching methods, based on learning theories and model, are now widely accepted. Inductive, problem-based, cooperative and active teaching and learning styles already proved their efficacy. New teaching methods are concerned with not only covering the course materials but also developing creativity, decision making, communication, planning and managerial skills among the students.

Approaches to the engineering laboratory courses are also changing. Instead of pre-designed lab experiments, students are now asked to design, run and analyze their own experiments to study a described phenomenon. Students are assigned in different roles as coordinator, analyst, project manager, operations manager, research and development manager and health-safety-andenvironmental affairs manager, [13, 14]. The roles rotate from one experiment to another, to facilitate development of teamwork skills like leadership, time management, conflict resolution etc. [14].

Engineers of the future need more than just a sound technical background to be successful. In course of solving engineering problems they will need to interact effectively with people of various backgrounds. Therefore, engineering education must offer the students a compelling context for engineering design, a multi-disciplinary team experience, sufficient time to learn and practice professional skills, personalized mentoring and exciting technical challenges [15]. On the other hand, non-profit organizations like schools, museums, local government offices are going to face a future where technology is going to play a big part. Such organizations may not have the 
budget to acquire technological solutions they need. Programs are now being designed to facilitate both the engineering students and the community. Under such programs, students earn academic credits to provide technological solutions to the problems identified by the community. After establishing the students-community partnership a team is formed comprising of students from many engineering disciplines as well as non-engineering disciplines, depending on the project's need. Comments like "It made me understand how every aspect of engineering (design, implementation, team work, documentation) come together" [15] or "No longer is engineering just a bunch of equations, now I see it as a means to help mankind" [16] from the participants in such programs clearly states its impact on the engineering students.

\section{PROPOSED APPROACHES}

\section{Academic Accreditation}

After successful completion of Higher Secondary Certificate (H.S.C) examination most of the students show interest to pursue for higher education in different disciplines. Seats available in the public universities are limited compared to the number of students completing H.S.C every year. To meet the increasing demand for higher education, the Government of Bangladesh allowed establishment of private universities through the Private University Act, 1992. The act provides guidelines and criteria for private universities mostly about the organization and structure of such universities. According to section 7 of the Private University Act, 1992, private universities must have a balanced and intensive syllabus approved by the University Grant Commission (UGC) and section 17 gives the syndicate the power to make statutes containing syllabus, teaching methods, etc [17]. However, these sections are not enough to maintain standard of education. Exploiting the loopholes in the Act, 1992 and the Amendment, 1998, a number of people have made higher education rather a business enterprise. Simultaneously, a few new public universities are also showing performances below par like those private universities.

Historically BUET is the first preference for the engineering candidates. However, in reality they hardly know the differences between a department of BUET and a similar department in any other university. To give a comprehensive idea the following information should be made available to the students: a) a clear understanding of engineering program objectives; b) what a graduate would learn from the program; c) does the faculty have sufficient qualifications (such as teaching experiences, ability to communicate, enthusiasm, engineering experiences, etc.) and can he/she provide proper guidance to the students; and d) last but not the least, does the university has proper classrooms, laboratories and necessary equipment.

Recently Institute of Engineers', Bangladesh (IEB) has established the Board of Accreditation for Engineering and Technological Education (BAETE). All five public engineering universities are excluded from the process. BAETE is going to check the compatibility of the other engineering departments of other universities in Bangladesh [18]. Among the universities, only the Civil engineering department at BUET had gone through accreditation process by the UK Joint Board of Moderators [6]. So, the frame of reference set by BAETE is yet to be standardized. In addition, a formal ranking system among the engineering departments of different universities can be introduced, which would reflect educational and research standards of the individual department.

Proper accreditation of the academic institutions and departments will help the students to select their desired universities and departments. It will also help the employers to evaluate the degrees of the candidates and recruit the preferable one.

\section{Integrated Curriculum}

BUET is blessed with some of the best talents of the country. A limited number of students filtered out from thousands of talents produced by the education system of the country and get the opportunity to get admission in BUET (in 2007, numbers of undergraduate enrolment in BUET was only 855 , from approximately 70,000 eligible students, who successfully completed secondary level of education in science group [19]). But the overall performance of the students can not be said to be fully satisfactory as expected. Some part of the students perform very well, however, a significant portion cannot fulfil the desired level. Comparing what they are capable of and what they would have done in other fields of higher education, it is greatly disappointing. We can figure out some of the reasons behind: a) most of the students choosing a subject against their will; b) some of them are hesitant of their learning objectives or ultimate goal as they know little about their field of study (as example, a chemical engineering student has to wait till Level-1, Term-2 to learn what chemical engineering is); c) inadequate facilities for textbooks and journals; d) most of the students cannot make link between mathematics and sciences they learnt as a freshman with the engineering courses as well as with their futurecareers in engineering, which leads to selfdissatisfaction. Teachers, who lack skill and knowledge, also act as a spoiling factor.

The approach "integrated engineering curriculum" is to show the students relationship between basic science and engineering science. Many universities have already implemented integrated curriculum for 1st year students and now 
they are going for sophomore integrated programs [20]. The outcome of such integration is positive. Studies showed that students under such programs score better than the traditionally taught students up to $30 \%$ higher [21-24]. These students can retain more information they have learnt, and they do better in the following years [24]. It also helps the slow learners to gain confidence as the fellow students and instructors help them in the process and later prove themselves good students [24]. Doing such progress in traditional classes is less probable.

Integrated programs are designed through communication and collaboration among faculty members from different disciplines; as example, Drexel E4 (E4, Enhanced Educational Experience of Engineering students) faculty members came from thirteen departments including humanities, science and engineering [21]. Most valuable effect of such program is formation of a multidisciplinary learning community and also help the faculties to develop their understanding of learning and teaching.

\section{Effective Teaching}

To successfully deal with the challenges of the $21^{\text {st }}$ century engineers must possess three tools: knowledge, skills and attitude. According to Rugarcia et al., knowledge is the database of professional engineers and skills are the tools used to manipulate the knowledge in order to meet a goal dictated or strongly influenced by the attitudes [1] However, the volume of information is increasing rapidly and cannot be contained within single engineering curricula. Therefore, alongside delivering the knowledge, teachers are also needed to work on developing learning skills of the engineering students to make them independent, interdependent and lifelong learners.

"Principles first and then application", most engineering courses are taught in this manner. According to Felder and Silverman this is "Trust me" approach of education in which teachers teach theories and govern laws and hope students will be able to recall and use these theories as needed [25]. "Principle leading to phenomena" or "deduction" is not natural way of learning. The opposite of "deduction" approach is "induction", which is, "phenomena leading to principle". "Induction" is natural way of learning. We learn on our own from real situations, not from theories and principles. Inductive teaching is also known as discovery learning, problem-based learning and the case study method. Longer retention of information, improved abilities to apply principles, better problem solving abilities and increased capability for creative thinking are some of the benefits of inductive learning method.

Studies suggest that most engineering students are inductive learners and almost all teachers are deductive teachers [25]. Therefore, Inductive method integrated with conventional deductive method can be adapted to provide appropriate learning environment. An effective way is induction followed by deduction. Felder et al. proposed three simple steps: "begin with induction, proceeding by inference from specifics to generalities, and then switch to deduction" [26-28].

Beside that, developing values and ethical senses are also very important for the engineering students. Values and ethical senses make them think about the quality, the productivity and also their responsibilities towards environment and the community.

\section{Student Evaluation}

Classroom evaluation has greater psychological effects. It is very much important to extract the best out of the students. Appropriate classroom evaluation can help the students to find the hidden curriculum (answer-oriented approach to the course); afterwards they can allocate their effort with great efficiency [29]. Crooks pointed out seventeen short, medium and long term effects of classroom evaluation [30].

Classroom evaluation should be designed to support the learning styles of the students. Students learn in different ways from the classroom lectures. Many or most engineering students are visual, sensing, inductive, and active, and some of the most creative students are global. Felder and Silverman proposed five major learning styles of students, which are respectively: perception, input, organization, processing and understanding [25]. Class tests and assignments of an engineering course should be compatible to different learning skills to ensure the equal opportunity. Moreover, classroom assessment should target to improve engineering perceptions of the students, make them more creative and keep them attentive towards the course contents rather than let them chase hard the grade only.

In addition, using a proper marking scheme and giving regular feedback to the students is very important to ensure proper assessment and grading in a course. Regular feedback on exam script or report helps students to understand the common mistakes they make and gives them a chance to improve in the next exam or assignment. Mark distribution scheme is helpful for both the students and the examiners. For any certain course, mark distribution scheme of exam or report should be developed and strictly followed. For the clarity and better output it is important to let the students know the marking scheme prior to the exam or report submission. It helps students to design their answers as required and examiners to ensure consistency of marking reports/exam-papers.

\section{Application of Computer in Teaching}

The simplest use of computers in classroom is the media for instruction. A recent study suggests 
that though there are not much differences in students' Grade Point Average (GPA) because of the use of PowerPoint presentation, however, there are differences in the students attitude - their participation in classroom increase and they express their willingness to attend another course from the same instructor [31]. Preparation technique and contents of the presentation slides also have a significant effect on the outcome.

Studies suggest preparation prior to classroom lecture has an impact on student's learning [32-34]. Therefore, some universities are now providing slides associated with audio speech in advance via website so that the students can collect them, listen the records while going through the slides. This method of teaching facilitates the students' understanding of the topic. However, only a few of the BUET teachers have adapted multimedia as a method of instruction.

Other computer aided tools, such as, spreadsheets, equation solvers, and simulators have already proved their importance as secondary tools of teaching and learning. Spreadsheets, integrated with the engineering and numerical problem solving since 1987, are easy to learn and can reduce a lot of time and permit the students to think deeper [11]. Spreadsheets allow the teachers to assign openended problems. Spreadsheets come with graphing tools, which made spreadsheets almost obligatory. All symbolic algebra programs such as MATLAB, MAPLE, and Mathematica have similar advantages. However, significant time is required to be skilled with such programs.

Computer-based laboratories are more easily accessible than physical labs. When installed, the lab software can convert the computer as a well equipped lab. Software packages like, VUOL, Cyclepad, Vicher can be downloaded free of cost and used with full functionality. Some of the engineering faculties are also offering web-based virtual laboratories which are accessible for all, $24 \times 7$ [35-37].

However, virtualization of laboratories can never be an alternative to hands-on laboratory. A recent study suggests that adaptation of virtual experiments is only a good choice when the particular experimental unit is not available [38]. A combination of physical and virtual lab can be very useful; students will know how the equipment looks like, how it operates in the physical lab; moreover, in the virtual portion, they will have some knowledge about the computer interfaces which are very similar to the industrial control panels.

\section{Interaction with Industry: Share the Experience}

It is common that a certain number of engineering students gradually lose their interest on engineering courses due to lack of proper inspiration. Especially the newly admitted students may feel startled for not having clear idea about what they are expected to learn from an engineering course. Most of the times the engineering courses appear to the students as a series of mathematical equations and principles, and the students struggle to correlate those equations with real life engineering. Sometimes course teachers even could not help much due to time constraint or lack of engineering experiences. In such cases a well experienced engineer either from industry or academic with good engineering insight could be a better option to inspire the students. He or she can help a student to understand the engineering principles/facts and correlate those with real life engineering; and even motivate the students as a role model.

Different workshops can be arranged for the students inviting experience engineer(s) from industries as guest speaker to share diverse prospects as well as constraints of engineering world. He/she can even present different units or principles practiced in real life engineering. Academics with engineering experience can even facilitate the workshops and give presentation to make the topic easier to the students.

\section{Field Trip}

Field trips can be a very effective teaching method. Seeing real equipment would do lot better than reading and memorizing about the same equipment.

A field-trip does not always mean visiting an industry. A trip of such magnitude may require substantial time and work to set up. However, trips to the university power plant or the boiler house can be completed in few hours. Civil engineering students can visit nearby sites of new buildings; chemical/environmental engineering students can visit a local water/wastewater treatment plant and so on. Such trips can be arranged on regular basis and can provide concrete idea about the equipment and processes from the real engineers involved in the engineering operations.

\section{Multidimensional Competition}

Healthy and fair competitions among the students can make them more competitive and confident. The competition should be multidimensional to ensure the participation of students of different skills. Ongoing practice among the students is to completely focus on the course activities and try for a better grade. But above and beyond following the course curriculum a student can also prepare himself/herself as a good speaker, being able to prepare a good scientific presentation or even get the flavour of real life engineering.

Regular competition can be arranged in different forms, such as, poster competition, multimedia presentations, engineering projects, final year design and thesis, etc. Major objectives of these competitions should be inspiring the students to work as an active individual or team member, developing skill to produce scientific 
posters and being able to present any scientific issues to good number of audiences. Moreover, these competitions should stimulate a student to develop himself/herself more compatible or competitive as an engineer or potential researcher from the early stage of his/her engineering education. The evaluation committee for the competitions should comprise experts of different disciplines, such as, university academics, industry managers and professional engineers.

Poster or multimedia presentation competition can be opened for students of any academic year, classified into different groups and sub-groups. Any scientific principle, law, laboratory experiment, or engineering issue discussed in classroom can be the topic of such competitions. The rules, framestructures and contents of scientific poster/multimedia presentation should be fixed by the examiner panel according to the level of different groups.

Different project based competition can be organized through engineering programs. As example, every year Chemical Engineering department of Monash University organizes different programs for their fresh undergraduate students as well as for the high school graduated students and demonstrates different chemical engineering projects to promote chemical engineering. As a part of these programs they arrange different project based competitions. Similar project based competition can be arranged for the senior students by changing the degrees of difficulties.

Universities can also offer special reward for the best (or even best three) final year thesis and design team as recognition of their effort, and offer them special certificate or encourage them to pursue their thesis find-out to a journal/conference paper publication. This could be very much helpful at the early stage of their career either as an engineer or as a researcher.

Moreover, disciplines the students learn from these competitions are more valuable than winning or loosing the competition.

\section{Engineering Projects in Community Service}

Integration of community service-learning in engineering education can prepare our students to deal with issues ranging from economic development to poverty, the environment, healthcare, and energy. We need to design for them educational experiences that will strengthen them for this pivotal role. As the society continues to expect more from the graduating engineers it is becoming necessary to build a meaningful partnership between engineering and community. This is a crucial challenge for which the student will need to be groomed right from the initial years of the study in engineering and other technical subjects.
Students who opt for such projects could be grouped into multidisciplinary teams and under the guidance of the project teachers assigned community projects, which could include environmental cleanup, provision of potable water, design of simple structures, supervision of rural development projects, promotion of computer literacy and design of simple computerized systems, building of school laboratories with simple technological devices, provision of low-cost technical expertise, etc. Provision is to be made for awarding formal academic credit after evaluation. Such exercises could provide the participants with professional skills, including ability to work in a team environment, develop entrepreneurial sprit, communicate effectively, work with real customers, anticipate societal needs and manage projects. An additional aspect of such activities would be instilling ethical values in the mind of participants, which is so essential for leaving a lasting impression in a community [6].

\section{Promotional Activities to Attract Potential Students}

In Bangladesh, Engineering is one of the most lucrative fields of study for the students completing secondary level of education. Technical institutions like BUET have never had difficulties in attracting qualified applicants. As a result, the faculty never felt the urge to popularize or sell the benefits of engineering education to the public at large. But, a sense of complacency may be considered dangerous in the highly competitive globalized market place of the 21 st century.

Arranging seminars at the university premise as well as at selected secondary level institutions can draw a clear picture about engineering in the minds of the interested students. Faculty from different disciplines can promote themselves so that students know what they are choosing and why. Making the university and departments accessible for all, for a day annually can also make a permanent impression in the mind of the children's visiting with their parents as they will be able see the interesting features of engineering education.

\section{CONCLUSION}

To cope with rapid changes in engineering, renowned international universities are regularly going through re-evaluation of courses as well as adoption of new delivery modes. This paper discussed some of the approaches, which are already proven to stimulate students to become more focused on classroom education:

(A) Integration of engineering curricula with related fields of study

(B) Use of interactive and effective teaching methods

(C) Introducing computer as an effective teaching tool 
(D) Improving industry-university relationship to aid sustainable development

(E) Introducing promotional activities to motivate students

(F) Introducing community service-learning to develop ethical and social values of the students

Adopting such methodologies with precision will help to upgrade the course curriculum and implement new ideas to the engineering education of Bangladesh. The net result will be multidimensional, competent and conscious engineering graduates who will eventually lead the nation to a new era.

\section{REFERENCES}

1. Rugarcia, A., et al., The Future of Engineering Education I. A Vision for a New Century. Chemical Engineering Education, 2000. 34(1): p. 16-25.

2. Edens, K.M., Preparing Problem Solvers for the 21st Century through Problem-Based Learning. College Teaching, 2000. 48(2): p. 55-60.

3. Rashid, M.A., Engineering Education in East Pakistan in the Context of Modern Development. Journal of the Ahsanullah Engineering College, 1958. 8(1): p. 4-9.

4. Rahman, M.A. and A.S.M.A. Haseeb. Challenges of Research and Graduate Studies in Engineering at BUET. in National Symposium on Engineering and Technological Education. 2007. Dhaka, Bangladesh: DAERS, BUET.

5. Bari, M.F. International Linkage Programs of BUET. in National Symposium on Engineering and Technological Education. 2007. Dhaka, Bangladesh: DAERS.

6. Maumud, I. Re-engineering BUET for The Challenges of the 21st Century. in National Symposium on Engineering and Technological Education. 2007. Dhaka, Bangladesh.

7. Hoque, A.S.M.L. and M.I. Hossain. Dropout Rate at BUET: A Performance Indicator for the Evaluation of Higher Studies. in National Symposium on Engineering and Technological Education. 2007. Dhaka, Bangladesh: DAERS.

8. Annual Report. 1998-2003, Bangladesh University of Engineering \& Technology: Dhaka.

9. Stice, J.E., et al., The Future of Engineering Education IV: Learning How to Teach. Chemical Engineering Education, 2000. 34(2): p. 118-127.

10. Wankat, P.C. and F.S. Oreovicz, Teaching Prospective Faculty Members About Teaching: A Graduate Engineering Course. Engineering Education, 1984. 74(1): p. 85.

11. Wankat, P.C. and F.S. Oreovicz, Teaching Engineering. 1993, New York: McGraw-Hill.
12. Felder, R.M., Teaching Teachers to Teach: The Case for Mentoring. Chemical Engineering Education, 1993. 27(3): p. 176-177.

13. Roche, E.C. and D.B.V. Dongen. An Industrial Approach to the Unit Operations Laboratory Course. in ASEE Annual Conference \& Exposition. 1998. Seattle, Washington: ASEE.

14. Felder, R.M. and S.W. Peretti. A Learning Theory-based Approach to the Undergraduate Laboratory. in ASEE Annual Conference \& Exposition. 1998. Seattle, Washington: ASEE.

15. Coyle, E.J., L.H. Jamieson, and W.C. Oakes, EPICS: Engineering Projects in Community Service. Internation Journal of Engineering Education, 2005. 21(1): p. 1-12.

16. Coyle, E.J., L.H. Jamieson, and W.C. Oakes, Integrating Engineering Education and Community Service: Themes for the Future of Engineering Education. Journal of Engineering Education, 2006: p. 7-11.

17. The Private University Act. 1992, Bangladesh Gazette Extraordinary.

18. Board of Accreditation for Engineering and Technological Education: BAETE Home Page: http://www.baete.org.bd. [cited 2008 January, $8]$.

19. Ahmed, N., Education Scenario - Bangladesh, in Dr. Rashid Lecture. 2008, Bangladesh University of Engineering \& Technology: Dhaka.

20. Froyd, J.E. and M.W. Ohland, Integrated Engineering Curricula. Journal of Engineering Education, 2005. 94(1): p. 147-164.

21. Quinn, R.G. Implementing Large Scale Curriculum Changes - The Drexel Experience. in ASEE/IEEE Frontiers in Education. 1995. West Lafayette, Indiana: ASEE-IEEE.

22. Felder, R.M., et al. Update of IMPEC: An Integrated First-year Engineering Curriculum at N.C. State University. in American Soceity for Engineering Education Conference and Exposition. 1998.

23. Nelson, J. and S. Napper. Ramping Up an Integrated Engineering Curriculum to Full Implementation. in 29th ASEE/IEEE Frontiers in Education Conference. 1999. San Juan, Puerto Rico: ASEE-IEEE.

24. Roedel, R., et al. An Integrated, Project-based, Introductory Course in Calculus, Physics, English, and Engineering. in Frontiers in Education Conference. 1995. Atlanta, GA: ASEE-IEEE.

25. Felder, R.M. and L.K. Silverman, Learning and Teaching Styles in Engineering Education. Engineering Education, 1988. 78(7): p. 674681.

26. Felder, R.M., It Goes Without Saying. Chemical Engineering Education, 1991. 25(3): p. 132-133. 
27. Felder, R.M., et al., The Future of Engineering Education II. Teaching Methods that Works. Chemical Engineering Education, 2000. 34(1): p. 26-39.

28. Quah, E.B.H., C. Wardjiman, and M. Rhodes. Scaffolding First-Year Chemical Engineering Course with Project-Based Assessment. in Chemica Conference. 2007. Melbourne, Australia.

29. Gibbs, G. and C. Simpson, Conditions Under Which Assessment Supports Students' Learning. Learning and Teaching in Higher Education, 2004-2005. 1: p. 3-31.

30. Crooks, T.J., The Impact of Classroom Evaluation Practices on Students. Review of Educational Research, 1988. 58(4): p. 438-481.

31. Apperson, J.M., E.L. Laws, and J.A. Scepansky, The Impact of Presentation Graphics on Students' Experience in the Classroom. Computer \& Education, 2006. 47: p. 116-126.

32. ChanLin, L.-J., Animation to Teach Students of Different Knowledge Levels. Journal of Instructional Psychology, 1998. 25: p. 166-175.

33. Lee, A.Y., D.J. Gillan, and C.L. Harrison, Assessing the Effectiveness of a Multimedia-
Based Lab for Upper Division Psychology Students. Behavior Research Methods, Instruments, Computers, 1996. 28: p. 295-299.

34. Mayer, R.E. and J.K. Gallini, When is an Illustration Worth Ten Thousand Words? Journal of Educational Psychology, 1990. 82: p. 715-726.

35. Henry, J. Running Laboratory Experiments via the World Wide Web. in ASEE Annual Conference \& Exposition. 1998. Seattle, Washington: ASEE.

36. Henry, J. 24×7: Lab Experiments Access on the Web All the Time. in ASEE Annual Conference \& Exposition. 2000. St. Louis, Missouri: ASEE.

37. Shin, D., et al., Web-based interactive virtual laboratory system for unit operations and process systems engineering education. Computers and Chemical Engineering, 2000. 24: p. 1381-1385.

38. Wiesner, T.F. and W. Lan, Comparison of Student Learning in Physical and Simulated Unit Operations Experiments. Journal of Engineering Education, 2004. 93(3): p. 195204. 